\title{
BODY ORIENTATION IN DYADIC CONVERSATION OF RUSSIAN ALPINISTS AND SPECIAL OPERATION FORCES: EVIDENCE FOR DIFFERENCES IN IN-GROUP FAVORITISM?
}

\author{
Yulia Apalkova ${ }^{1}$, Marina L. Butovskaya ${ }^{1,2}$, Todd K. Shackelford 3 , Bernhard Fink, \\ ${ }^{1}$ Institute of Ethnology and Anthropology, Russian Academy of Sciences, Moscow, Russian \\ Federation \\ ${ }^{2}$ Social Anthropology Research and Education Center, Russian State University for Humanities, \\ Moscow, Russian Federation \\ 3Department of Psychology, Oakland University, Rochester, Michigan, USA \\ ${ }^{4}$ Biosocial Science Information, Biedermannsdorf, Austria \\ ${ }_{5}^{5}$ Department of Evolutionary Anthropology, University of Vienna, Austria
}

julia.apalkova@gmail.com

\begin{abstract}
In-group favoritism-a preference for members of one's group - may be evident in non-verbal behavior and may affect moral judgments. We recorded body orientation (towards vs. away from the conversation partner) in 139 dyadic conversations of male Russian alpinists ( 74 dyads) and members of the Special Forces (65 dyads) by scan sampling at a mountaineer base camp in Northern Caucasus (695 observations in total). In addition, we secured moral judgements from different samples of Russian alpinists $(n=65)$ and Special Forces $(n=61)$ at the same location. Special Forces more than alpinists showed body orientation towards their conversation partners and reported higher levels of loyalty and authority/respect. These findings may reflect particularly strong bonds between men involved in violent intergroup conflict, leading to in-group favoritism and related moral judgements.
\end{abstract}

Keywords: in-group favoritism, parochialism, body orientation, moral foundations, cooperation 


\section{INTRODUCTION}

The willingness to cooperate may be evident in nonverbal cues such as interpersonal distance and body orientation in conversation (Kühl \& Szech, 2018). Body orientation toward a conversational partner (sociopetality) may indicate a stronger interest in cooperation (Hall, 1963). We investigated body orientation in dyadic conversation among male Russian alpinists and members of the Special Forces. Special Forces are involved in armed conflict whereas alpinists are not; thus, the former may share stronger bonds, which would be evident in nonverbal cues.

Parochial altruism theory (Choi \& Bowles, 2007) suggests that intergroup conflict has played a role in the formation of bonds between in-group members. Intergroup conflict can facilitate group cohesion and lead to xenophobia (Rush, 2014; Silva \& Mace, 2015) and ingroup favoritism (Fu et al., 2012). Members of a threatened group can form stronger relationships also with non-kin members, who become "fictive" kin (Abou-Abdallah et al., 2016; Whitehouse et al., 2014). In-group favoritism also can affect moral judgements. In the context of frequent intergroup conflicts, there are moral norms that presuppose support for the group in many types of conflicts, including war and terrorism (Atran, 2012).

We hypothesized that in dyadic conversation members of Special Forces would show greater sociopetality (Hall, 1963) than alpinists; that is, greater body orientation towards a conversation partner. In addition, we expected Special Forces to score higher than alpinists in moral foundations, especially loyalty and authority/respect (Graham et al., 2011; Haidt \& Joseph, 2007).

\section{METHODS}

\section{Participants}

We recorded body orientation of men in 139 dyadic conversations at a mountaineer base camp in Northern Caucasus, Kabardino-Balkaria, Russia, as part of a larger anthropological study (see Apalkova et al., 2020, for a related report). Conversational partners were either alpinists or members of the Special Forces (identified by uniforms), respectively. In addition, we collected information about moral foundations at the same location from 126 men, ages $19-47$ years $(M=32.83, S D=6.53)$. Participants were Russians citizens (by selfreport), either alpinists ( $n=65$, ages 19-47 years, $M=32.37, S D=7.90)$ or members of the Special Forces $(n=61$, ages $24-46$ years, $M=33.31, S D=4.65)$. These participants were not matched with those in the observational study following the study protocol, which prioritized (anonymous) behavioral observation recordings and did not allow securing photographs of Special Forces.

\section{Body orientation observation}

The body orientation of men in dyadic conversations was observed daily for two weeks in August 2018, during daylight hours from 7.00 am to $6.00 \mathrm{pm}$, and outside near accommodation areas. The principal investigator (Y.A.) and a female assistant recorded body orientations using the Sociofugal-Sociopetal (SFP) axis notation code (Hall, 1963). The SFP describes the spatial orientations of individuals in interaction. Zero (and 8; "maximum sociofugality") are placed at North, 2 at East, 4 at South, 6 at West. We recorded positions 0 to 4 . Positions 0 and 1 represent two subjects face to face ("maximum sociopetality"); these positions suggest direct communication. In position 2, two subjects 
are standing at right angles so they can have eye contact, but if they look straight ahead, they see each other peripherally. This position is more casual and suggests less interaction engagement. Position 3 and 4, in which the subjects stand side-by-side with the NorthSouth axis running through a parallel to their shoulders or the angle formed by the axis is $>135^{\circ}$, suggest that there is no eye contact and the level of engagement in conversation is lower than in positions 0 to 2 (Figure 1 ).

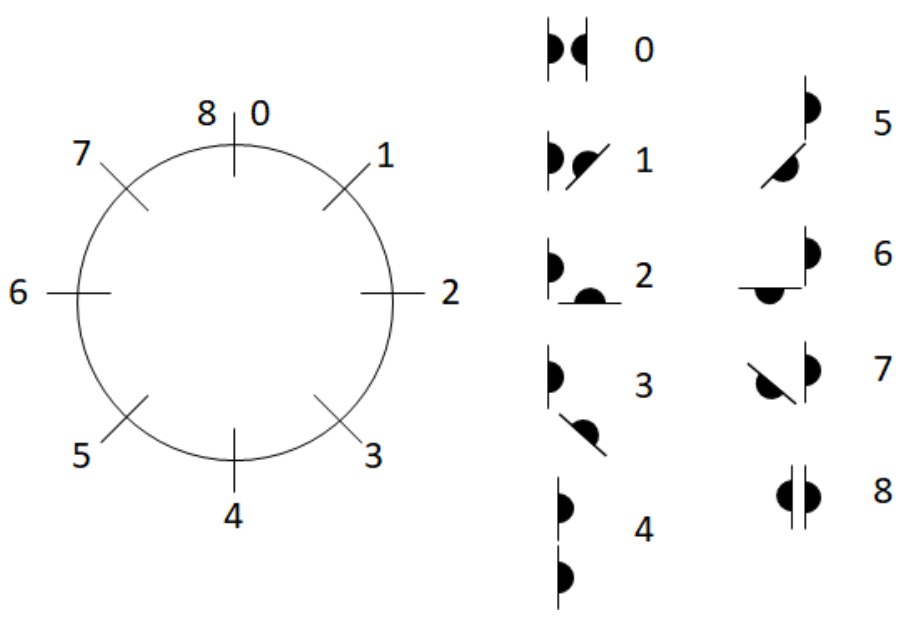

Figure 1: Sociofugal-Sociopetal (SFP) axis notation code for body orientations (re-drawn after Hall, 1963).

Each pair was observed 5 times by scan sampling (every minute) over 5 min and the frequency of body positions 0-4 was recorded. We combined for analysis positions 0 and 1 into the category of orientation "toward" the partner and positions 2-4 into the category of orientation "away" from the partner. Of 139 dyadic conversations, 65 were between members of the Special Forces, and 74 between alpinists. We did not record mixed dyads (i.e. alpinists in conversation with Special Forces) although they may have occurred. Thus, the total number of observations was 325 for Special Forces and 370 for alpinists.

\section{Moral Foundation Questionnaire}

To assess moral foundations, we used the short (20-item) version of the Moral Foundation Questionnaire (MFQ; Graham et al., 2011; Haidt \& Joseph, 2007), i.e. the MFQ20. The scale measures an individual's endorsement of five psychological foundations of morality: i) care/harm (concerns about the suffering of others), ii) fairness/cheating (concerns about unfair treatment), iii) loyalty/betrayal (concerns about obligations of group membership), iv) authority/subversion (concerns about social order), and v) sanctity/degradation (concerns about physical and spiritual contagion). We administered the Russian language MFQ20, obtained from moralfoundations.org.

Participants completed the survey privately and after the behavioral observation at the camp was completed. The survey data were collected during one week. Participants were recruited verbally by the principal investigator (Y.A.) and, if they agreed to participate, a time/date for data collection was scheduled (normally within 1-2 days). After arrival at the testing location (an office in the camp), participants were introduced to the procedure. Written consent was obtained from all participants. The participants received US\$10 compensation after completing the questionnaire. All participants were debriefed after the 
completion of the data collection. They received contact details in case of questions about the study.

\section{RESULTS}

Body orientations correlated strongly and positively across the five times of assessment (Spearman rho: rhos $>64, p s<.001)$. We therefore summed the counts over time for toward and away orientations. For alpinists, the counts of body orientations away from the conversation partner were higher than for orientations toward the conversation partner [away $M d n=4(0-5)$, toward $M d n=1$ (range 0-5), Wilcoxon-test: $Z=2.81, p=.005, r=$ 0.33]. The opposite pattern was found for Special Forces, although this difference was not significant [toward $M d n=4(0-5)$, away $M d n=1(0-5), Z=0.98, p=.329, r=0.12$ ] (Figure 2).

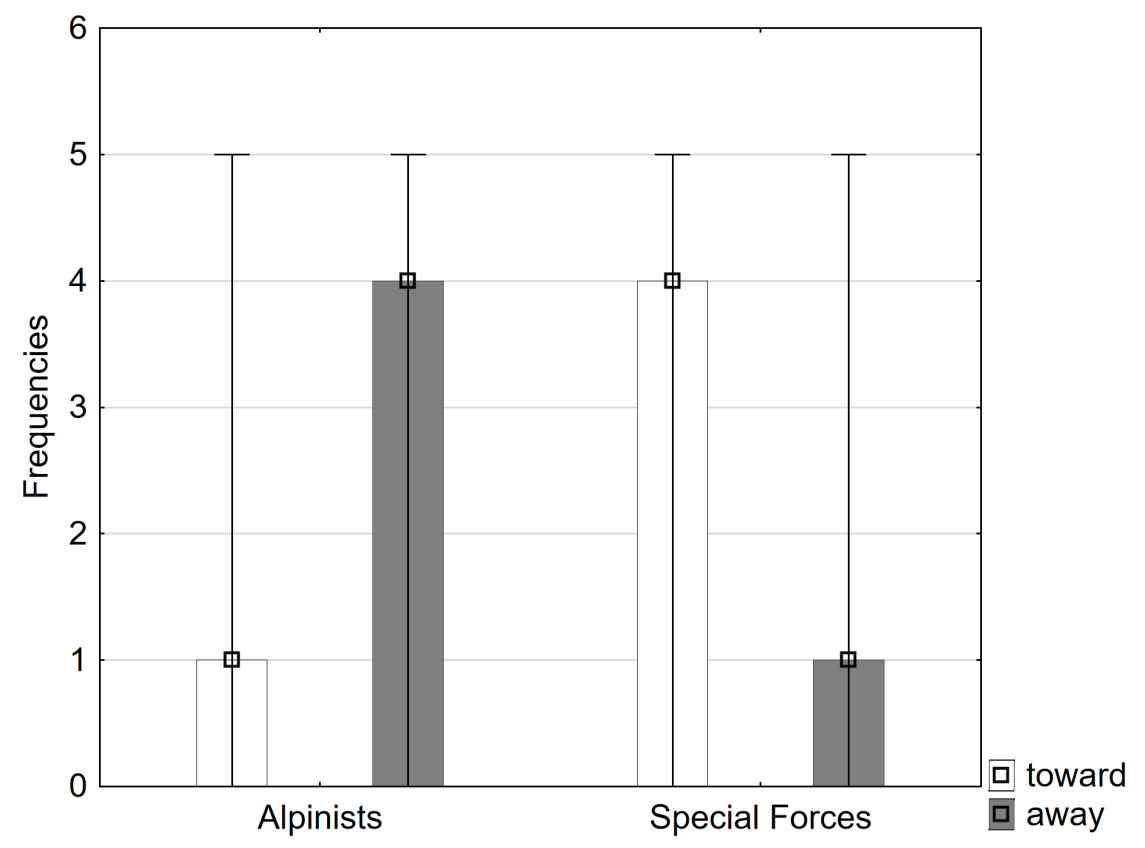

Figure 2: Box plot of frequencies (summed counts across five times of assessment) of body orientations toward and away from the conversation partner in alpinists and Special Forces.

A Mann-Whitney $U$-test showed that alpinists scored lower on all MFQ20 measures compared to Special Forces, with significant differences for three of the five dimensions [care/harm: $M d n=13$ (5-18) vs. 14 (6-20), $Z=-2.80, p=.005, r=0.25$; loyalty/betrayal: $M d n=13$ (4-20) vs. 17 (9-20), $Z=-5.89, p=.001, r=0.52$; authority/subversion: $M d n=$ $10(0-20)$ vs. 14 (4-20), $Z=-5.68, p=.001, r=0.51]$ but no significant differences for fairness/cheating $[M d n=16(6-20)$ vs. $17(11-20), Z=-1.18, p=.235, r=0.11]$ and sanctity/degradation $[M d n=14(0-20)$ vs. $15(6-20)$, vs. $Z=-1.85, p=.064, r=0.16]$. 


\section{DISCUSSION}

Our findings show that in dyadic conversation, male alpinists more than members of Russian Special Forces tend towards sociofugality (i.e. body orientation away from a conversation partner). Consistent with previous reports on nonverbal cues to cooperative behavior and trustworthiness (Kühl \& Szech, 2018; Oda et al., 2009), we suggest that the observed difference in patterns of body orientation reflects a difference in the propensity for in-group favoritism between alpinists and Special Forces. This difference may have consequences for moral foundations. Members of the Special Forces more than alpinists endorsed the foundations of loyalty and authority/respect.

These phenomena are not confined to humans. Across taxa, in-group favoritism is widely observed (Masuda \& Fu, 2015). It is a central aspect of human psychology (Fu et al., 2012), also because of its consequences for the development of social norms and altruistic behaviors (Bernhard et al., 2006). Some scholars suggest that in addition to social norms for food sharing or cooperative hunting, participation in intergroup conflicts has facilitated within-group interaction and cohesion (Choi \& Bowles, 2007; Masuda \& Fu, 2015). Intergroup conflict and violence can lead to morality shifting and may change moral principles of harm and fairness to those of loyalty and authority (Leidner \& Castano, 2012). Special Forces are involved in armed inter-group conflict whereas alpinists are not. This may explain, at least in part, the higher scores in moral foundations of Special Forces compared to alpinists and the related observations of differences in body orientation patterns between these groups.

However, other aspects may contribute to the observed differences between alpinists and Special Forces. Apalkova et al. (2020) reported in the same study location and groups (but with different individuals) personality differences between alpinists and Special Forces, suggesting that risk-taking depends on professional context (alpinists > Special Forces). Alpinists scored higher than Special Forces in neuroticism and openness, but lower in extraversion, agreeableness, and conscientiousness. In addition, alpinists scored higher in aggression compared to members of the Special Forces. It is unclear whether disposition or self-selection better explains the behavioral differences, which seem also to be displayed in nonverbal cues (as the findings of the present study suggest). A limitation of the present study is that we were unable to secure information about the familiarity and social closeness of group members. It can be assumed that both alpinists and Special Forces have a record of spending time together - either for training purposes or expeditions/combat. We consider it worthwhile to add a measure of perceived social closeness (e.g., Gächter et al., 2015) in future studies on the topic in addition to the objective assessment of familiarity among group members.

In conclusion, our findings suggest that the context-dependent variability of bonds among members of male groups is evident also in nonverbal cues and could be interpreted in support of previous reports on the endorsement of loyalty and authority/respect depending on involvement in intergroup conflicts. Future research should clarify the role of personality and social closeness in predicting group differences in male bonds from intergroup conflict and the consequences for in-group favoritism and related moral judgements. 


\section{ACKNLOWEDGEMENTS}

We thank Daria Khizhnyak for her assistance with the data collection in the mountaineer base camp in Northern Caucasus. This research was supported by an Owen Aldis Scholarship of the International Society for Human Ethology awarded to YA.

\section{CONFLICT OF INTEREST}

The authors declare that there is no conflict of interest.

\section{DATA AVAILABILITY}

The data set analysed and presented in the current study are available from the corresponding author on reasonable request.

\section{ETHICAL STATEMENT}

The study was conducted under the ethical principles of the Declaration of Helsinki for research with human subjects. The study protocol was approved by the Institute of Ethnology and Anthropology, Russian Academy of Science, Moscow, and permission was obtained from the director of the mountaineering camp.

\section{AUTHOR CONTRIBUTIONS}

YA, BF and MB designed the study. YA collected the data. YA and BF analyzed the data. MB provided resources and supervision. YA prepared the original draft of the manuscript. All authors contributed to writing and editing and approved the manuscript for its intellectual content.

\section{REFERENCES}

Abou-Abdallah, M., Kashima, Y., Harb, C. (2016). "Brothers" in arms: Does metaphorizing kinship increase approval of parochial altruism? Journal of Cognition and Culture, 16(1-2), 37-49. $\underline{\mathrm{DOI}}$

Apalkova, Y., Butovskaya, M.L., Shackelford, T.K., \& Fink, B. (2020). Personality, aggression, sensation seeking, and hormonal response to challenge in Russian alpinists and special operation forces. Personality \& Individual Differences, 110238. DOI

Atran, S. (2012). War, martyrdom, and terror: Evolutionary underpinnings of the moral imperative to extreme group violence. In: S. C. Roberts (Ed.), Applied Evolutionary Psychology (pp. 222-238), Oxford: Oxford University Press. DOI

Bernhard, H., Fischbacher, U., \& Fehr, E. (2006). Parochial altruism in humans. Nature, 442(7105), 912-915. DOI

Choi, J. K., \& Bowles, S. (2007). The coevolution of parochial altruism and war. Science, 318(5850), 636-640. DOI

Fu, F., Tarnita, C. E., Christakis, N. A., Wang, L., Rand, D. G., \& Nowak, M. A. (2012). Evolution of in-group favoritism. Scientific Reports, 2, 460. DOI 
Gächter, S., Starmer, C., \& Tufano, F. (2015). Measuring the closeness of relationships: a comprehensive evaluation of the 'Inclusion of the Other in the Self' scale. PLoS ONE, 10, e0129478. DOI

Haidt, J., \& Joseph, C. (2007). The moral mind: How 5 sets of innate intuitions guide the development of many culture-specific virtues, and perhaps even modules. In: P. Carruthers, S. Laurence, \& S. Stich (Eds.), The Innate Mind (pp. 367-391). New York: Oxford University Press. DOI

Graham, J., Nosek, B. A., Haidt, J., Iyer, R., Koleva, S., \& Ditto, P. H. (2011). Mapping the moral domain. Journal of Personality and Social Psychology, 101(2), 366-385. DOI

Hall, E. T. (1963). A System for the Notation of Proxemic Behavior. American Anthropologist, 65(5), 1003-1026. DOI

Kühl, L., \& Szech, N. (2018). Physical distance and cooperativeness towards strangers. CESifo Working Paper Series No. 6825. Available at SSRN: https://ssrn.com/abstract=3127363.

Leidner, B., \& Castano, E. (2012). Morality shifting in the context of intergroup violence. European Journal of Social Psychology, 42, 82-91. DOI

Masuda, N., \& Fu, F. (2015). Evolutionary models of in-group-favoritism. F1000Prime Reports, 7, 27. $\underline{\text { DOI }}$

Oda, R., Naganawa, T., Yamauchi, S., Yamagata, N., \& Matsumoto-Oda, A. (2009). Altruists are trusted based on non-verbal cues. Biology Letters, 5(6), 752-754. DOI

Rusch, H. (2014). The evolutionary interplay of intergroup conflict and altruism in humans: A review of parochial altruism theory and prospects for its extension. Proceedings of the Royal Society of London, Series B, Biological Sciences, 281(1794), 20141539. DOI

Silva, A. S., \& Mace, R. (2015). Inter-Group conflict and cooperation: Field experiments before, during and after sectarian riots in Northern Ireland. Frontiers in Psychology, 6, 1790. DOI

Whitehouse, H., McQuinn, B., Buhrmester, M., \& Swann, W. B. Jr. (2014). Brothers in arms: Libyan revolutionaries bond like family. Proceedings of the National Academy of Sciences U.S.A., 111(50), 17783-17785. DOI 